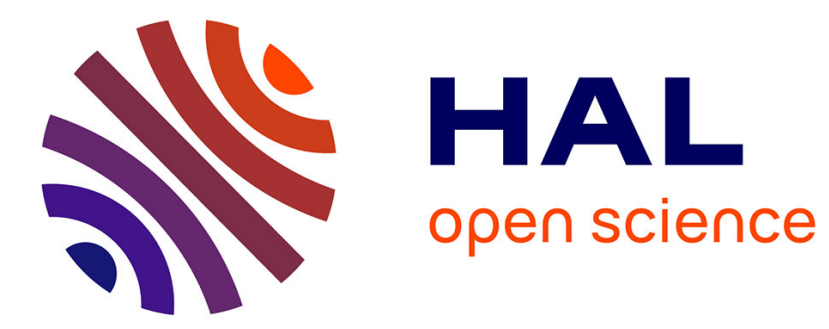

\title{
Biomimetics, where are the biologists?
}

Eliot Graeff, Nicolas Maranzana, Améziane Aoussat

\section{To cite this version:}

Eliot Graeff, Nicolas Maranzana, Améziane Aoussat. Biomimetics, where are the biologists?. Journal of Engineering Design, 2019, pp.1-22. hal-02269920

\section{HAL Id: hal-02269920 \\ https://hal.science/hal-02269920}

Submitted on 23 Aug 2019

HAL is a multi-disciplinary open access archive for the deposit and dissemination of scientific research documents, whether they are published or not. The documents may come from teaching and research institutions in France or abroad, or from public or private research centers.
L'archive ouverte pluridisciplinaire HAL, est destinée au dépôt et à la diffusion de documents scientifiques de niveau recherche, publiés ou non, émanant des établissements d'enseignement et de recherche français ou étrangers, des laboratoires publics ou privés. 


\title{
Biomimetics, where are the biologists?
}

\author{
Eliot Graeff (D), Nicolas Maranzana (D) and Améziane Aoussat
}

LCPI, Arts et Métiers ParisTech, Paris, France

\begin{abstract}
Engineering design, as the science framing the practice of design through the elaboration of tools and processes, is constantly evolving towards new innovative strategies. To thrive in their extremely competitive environment, it appears that both industrial and natural worlds are highly dependent on innovation, optimisation and selection. These commonalities have led designers to look to living beings for inspiration. This innovation strategy, referred to as biomimetics, isn't a new approach but its methodological aspects are still under development. This article deals with biologists' contribution throughout the biomimetic design process. After introducing the context and the experimental protocol, we investigated the impact of possessing a background in biology during the practice of biomimetics and compared our findings with experts' opinion. The main idea of this article is to show that to forego the integration of biologists is highly restrictive and may be one of the reasons explaining the difficulties of implementing biomimetics in the industrial context. Hence, this article argues for a new methodological framework taking into account biologists, allowing biomimetic teams to become truly interdisciplinary.
\end{abstract}

\section{KEYWORDS}

Biomimetics; descriptive models of the design process; transdisciplinarity; design teams; biologists

\section{Introduction}

\section{Biomimetics is defined as}

the interdisciplinary cooperation of biology and technology or other fields of innovation with the goal of solving practical problems through the function analysis of biological systems, their abstraction into models and the transfer into and application of these models to the solution. (ISO/TC266 2015)

Over the past decades, biomimetics has established itself as one of the most promising strategies to support innovative and environment-friendly products (Vincent et al. 2006; Hwang et al. 2015; Bar-Cohen 2006). Many studies have evaluated such processes and shown that they allow a greater novelty of solutions and thus generate a larger amount of innovative products (Keshwani et al. 2017; Ahmed-Kristensen, Christensen, and Lenau 2014).

CONTACT Eliot Graeff $\otimes$ eliot.graeff@ensam.eu

$(1)$ https://doi.org/10.1080/09544828.2019.1642462 
However, biomimetic design processes keep facing a fundamental trade-off between integrating biologists and finding ways to practice biomimetics without them. Biologists potentially constitute both the greatest asset and the greatest challenge of biomimetics. It has always been seen in interdisciplinary fields that the benefits of diversity comes with strong barriers in terms of communication and understanding between actors (Schöfer 2015; Schöfer et al. 2018). In the case of biomimetic design, a quick review of the existing tools and processes raises the following question: where are biologists? Most of the tools are designed to be used by engineers, all processes are meant to be followed by engineers and the resulting feeling is that biologists aren't considered in the methodological equation of biomimetics.

On account of the field's intrinsic need for biological knowledge, the current strategy is to develop tools, such as databases of biological strategies (Deldin and Schuknecht 2013; Nagel et al. 2010; Vincent et al. 2006). So far, this process works thanks to the relative novelty of the approach and low number of practitioners. The biggest database of biological strategies is AskNature which was created in 2008 and gathers 1671 biological strategies and 201 inspired ideas (Biomimicry Institute 2002). Even if the database is enlarged little by little, there is a real need to hasten this process in order for it to represent a viable solution in the long run (Vandevenne et al. 2015). Biomimetic design teams that directly include a biological expertise (i.e. an actor from natural sciences) may be the only coherent way to consider biomimetic as a long-term design strategy (Lenau 2009; Snell-Rood 2016; Schöfer et al. 2018; Chirazi et al. 2019).

After the presentation of the context and the hypothesis, this article deals with the following research question: Facing the current biomimetics' methodological framework, does knowledge in biology represent an asset for the practice of biomimetics? Through a case study carried out on the insulation of container homes in Ivory Coast and the abovepresented biomimetic tool, AskNature, a comparative analysis of the results obtained by students, with a background in engineering or in biology will be detailed. Then, they will be compared with the experts' opinion collected through a survey. With the aim of bringing out the fundamental question of the biologist's role in the biomimetic process, the contribution of this article is to underline the need to considerate biologists during both the practice of biomimetics and engineering design surrounding biomimetics.

\section{Context}

Through an overview of some common points between current design challenges and life's innovation mechanisms, this section addresses the question of the origin of the biomimetic process and underlines its crucial need for a methodological framework.

\subsection{Modern design challenges}

Many consider the alignment of product design and sustainable development as one of the greatest modern challenges (Bourgeois 2007; Sachs 2015). Indeed, whereas innovation remains one of the main levers for competitiveness, decades of pressing scientific warnings made governments and companies progressively realise that climate change and its impact on our society will dictate the centuries to come (IPCC 2014). In a world where the use of energy and raw materials will have to be minimised and where waste stream will need to 
be drastically reduced, our ability to design entirely new innovation strategies will be one of the keys to success.

Engineers often refer to design theories to solve design problems. Among these theories, which outline the current framework of design practice, a significant number is composed of problem-solving strategies that include abstraction processes (Lee, Pries-Heje, and Baskerville 2011). This part of the process aims at considering the design problem with a different perspective through its formalisation into theoretical models: Universal Design Theory (Grabowski, Lossack, and El-Mejbri 1999), Synectics (Gordon 1961), TRIZ (Altshuller 1984), etc. Once modelized, the given set of constraints and objectives are compared with those of solved cases from the same or other scopes of practice. This analogical thinking can be extremely powerful but requires an important source of resolved dilemmas to reach its full efficiency. The context above-mentioned, leads us to look for a prism through which design teams will be able to generate breakthrough innovations combining strong technical advantages and sustainability. Since the survival of living beings depends on innovation guided by biological rules, the biomimetic approach, as the extraction of biologic strategies to create analogic innovation, can offer such a prism (Helfman Cohen and Reich 2016). Looking at the strategies and adaptations of living beings appears to be a formidable learning tool for us to consider, as an endless reservoir of solved puzzles (Bila-Deroussy 2015).

\subsection{Bio-inspiration, a wish to learn from living beings}

Bio-inspiration is not a new strategy. The living world was often an object of comparison and a source of inspiration during the development of antic societies (Vincent et al. 2006; Lenau 2009) and has led to several scientific and design breakthroughs throughout history (Richter, Wells, and Kemp 2008; Eggermont 2015; Guerrero, Maestro, and Bottaro 2012; Magyar et al. 2017), etc. From aeronautics (Bar-Cohen 2012) to the biomedical field (Zhang 2012; Boeuf 2007), biomimetic success stories along with the dissemination work of iconic figures, such as Benyus (1997), granted bio-inspiration an international recognition. This increasing interest of the global engineering community also uncovered the lack of tools, processes and methods on bio-inspiration, leading engineers to formalise a bio-inspired design process in order to systemise its use.

\subsection{The need for the formalisation of biomimetic processes}

The inherent difficulty of such an interdisciplinary and unframed field is firstly the communication between the different actors. In 2015, to prevent any misunderstandings researchers developed a strict linguistic definition of the most common, and often mixed up, terms referring to the field: bio-inspiration, bionic, biomimicry and biomimetics (ISO/TC266 2015). Based on these standards, this article will focus on biomimetics.

Biomimetic processes are based on two types of approaches. Either the design is conceived after a biological discovery, leading to a new product often with a high added value: the biology push approach (ISO/TC266 2015), or biomimetics is used as a problem-solving process: the technology pull approach (ISO/TC266 2015). As the core of engineering design in the industry, the formalisation of biomimetic methods and tools, has been focusing on this problem-solving approach. A great number of methods have been designed to help 


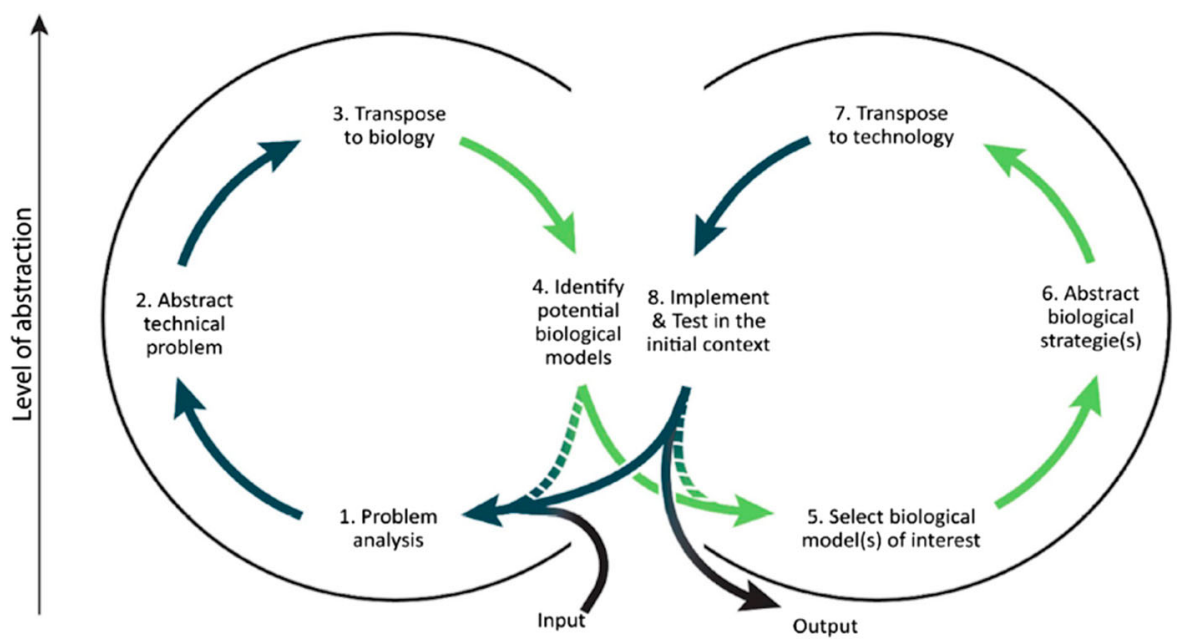

Figure 1. The unified technology-pull biomimetic process from Fayemi et al. (2014). (colour online)

implement a technology pull approach, The procedural model of doing bionics (Lindemann and Gramann 2004), Biomimetic design methodology (Lenau 2009), Problem-driven analogical process (Goel et al. 2014), etc. These methods can be described with the same eight main steps (Fayemi et al. 2014). As a result, Fayemi proposed a unified technology pull biomimetic process (Figure 1) which constitutes the methodological framework of our study. Despite these methodological improvements, the need for new tools soon emerged. Indeed, the lack of biological knowledge led engineers to face a limitation with such processes: find and extract biological strategies, functions, shapes, etc. A great number of tools have been conceived to deal with this issue, leading to the creation of tool-based methods - Idea-Inspire process (Chakrabarti et al. 2005), Biologically inspired concept generation (Nagel et al. 2010) - or to the improvement of existing processes.

Tools used in biomimetic design have mainly three origins (Fayemi 2016):

- engineering, like 5-Whys (Ohno 1978) or Technical contradictions (Altshuller 1984),

- biology, like 16 Patterns of Nature (Hoagland and Dodson 1995) or Functional modelization (Tinsley et al. 2007),

- biomimetics, like SAPPhIRE (Chakrabarti et al. 2005) or BIOTRIZ (Vincent et al. 2006).

It has to be specified that the tools that are said to come from biology, are neither biological tools nor tools designed to be used by biologists. They have been mainly designed for engineers to learn about biological findings. Wanieck et al. (2017) performed a classification and analysis of more than 40 tools. As often in engineering design, the increasing number of tools leads the user into an unclear path as it becomes more complicated to choose which tool to use, and under which conditions (Lahonde 2010).

This formalisation of the biomimetic process progressively highlights a contradiction with both the theoretical and practical aspects: the need for biologists is underlined in the literature but the methodological framework hasn't been designed to include these unusual profiles. 


\section{The biologist's role in biomimetic processes}

\subsection{A paradoxical consensus leading to our research question}

According to Wanieck et al. (2017), the step of the biomimetic process that holds the greatest numbers of tools is the step of identification of the biological model ( 21 tools) leading the author to conclude 'This fact also strengthens the necessary role of biologists in the field of biomimetics'. Paradoxically, most of those tools are designed by engineers, using engineering references and techniques and consequently appear to be made for engineers, not for biologists. Thus, it becomes clear that the overall tendency is to delay biologists' intervention or even to replace biologists by tools, without dealing with their tricky integration into the biomimetic process. Therefore, tools are getting more numerous and complex to compensate for the lack of biological knowledge, which leads us to the research question of this article: Facing the current biomimetics' methodological framework, does knowledge in biology represent an asset for the practice of biomimetics? As we've seen in the state of the art, some famous experts have been advocating for decades for biologists' inclusion. However, this inclusion isn't the main focus of the engineering design research on biomimetics. As a result, they are still poorly integrated and largely considered as external resources while biomimetic processes and tools are being designed. Thus, the aim of this article is to gather experimental data and experts' point of view on biologists' contribution during the practice of biomimetics. This substantiated answer should help foster the research effort towards the integration of profiles from natural sciences as a relevant improvement for biomimetic design teams and processes. In order to discuss this topic, we focused on one of the most comprehensive and complete biomimetic databases (Faludi 2017; Deldin and Schuknecht 2013): AskNature (Biomimicry Institute 2002).

\subsection{Hypothesis}

This article deals with the contribution of biologists in the biomimetic process. Our hypothesis is that having an expertise in biology increases the biomimetic process efficiency. Indeed, we think that a background in biology will lead to a quicker, deeper and more reliable search of biological strategies. Moreover, we expect tools like AskNature to be used for different goals, depending on the user's level of biological knowledge. Where, at a first level engineers can get inspired from living beings to increase the innovation potential of creativity steps, a background in biology may lead to a deeper, more comprehensive and more accurate understanding of biological strategies, required for the abstraction and the direct transposition of biological mechanisms into technology.

In order to test our assumptions, we designed a case study on the insulation of container housing in the Ivory Coast, and a survey to collect experts' opinion.

\section{Materials and methods}

\subsection{Materials}

The case study presented in this article aims at developing an insulation for former shipping containers so that they can be turned into comfortable houses in Ivory Coast. Students had access to a short description of the case study and to basic data about Ivory Coast and 
the context of the project: climatic information (type of climate, monthly temperatures and precipitations), characteristics of the containers and of the planned village of containers, expectation of the industrial actor in terms of aesthetic.

The first tool, the Biomimicry Taxonomy (Figure 2), was also distributed to the participants. This open-access tool was created by the Biomimicry 3.8 Institute to transpose technical problems from non-biological fields into requests suitable for AskNature (Baumeister 2014). The Biomimicry Taxonomy is constituted of three levels:

- Group, which refers to the overall function (ex: protect from physical harm),

- Sub-Group, which refers to a specificity linked with the overall function (ex: protect from living threats),

- Function, which refers to a more specific case in the sub-group (ex: protect from Fungi).

This multi-scale taxonomy acts as a skeleton for AskNature and enables the user to formulate requests using a common linguistic frame, directly connecting technical issues with AskNature data. AskNature is an open-access database created by the Biomimicry 3.8 Institute (Biomimicry Institute 2002). It lists biological organisms, strategies, functions and more generally characteristics. This data is then made readily available through an intuitive search engine.

For purposes of accessibility to consequent samples, our experiment compares the results obtained by individual students with a background in biology versus those obtained

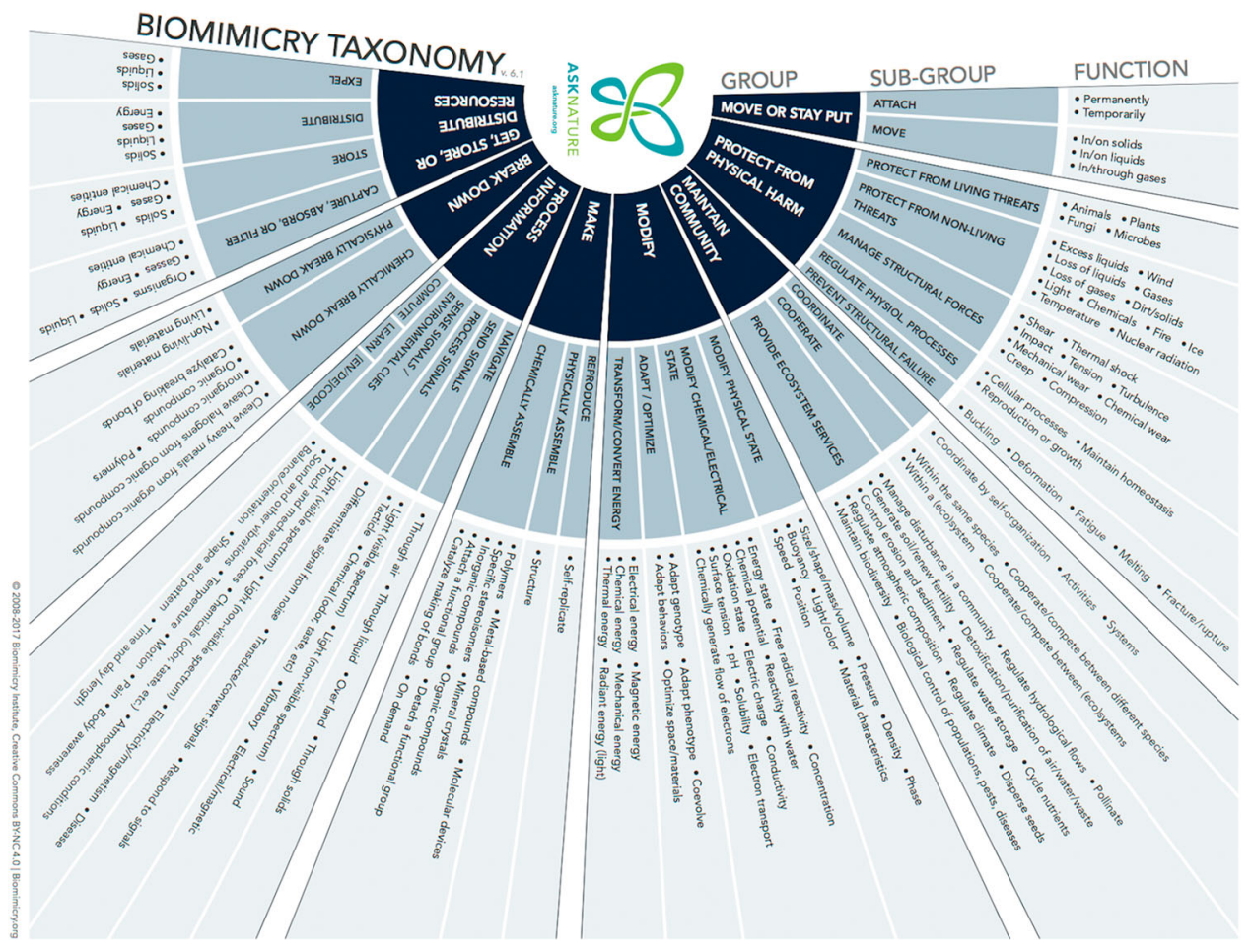

Figure 2. The Biomimicry Taxonomy (Baumeister 2014). (colour online) 
Table 1. Sample characteristics and distribution.

\begin{tabular}{lccc}
\hline Profiles (and scientific training) & Level of education & $\begin{array}{c}\text { Biomimetic } \\
\text { knowledge }\end{array}$ & Number of students \\
\hline $\begin{array}{c}\text { Engineers (Industrial engineering, product design, } \\
\text { interaction design, creativity, etc.) }\end{array}$ & Masters degree (M2) & None & 21 \\
$\begin{array}{c}\text { Biologists (Agronomy, molecular biology, } \\
\text { physiology, soils sciences, environment, etc.) }\end{array}$ & Masters degree (M1 \& M2) & None & 21 \\
\hline
\end{tabular}

by engineering students instead of actual professionals. The experiment has been conducted with a total sample of forty-two students divided as explained in Table 1.

At each step of the process, participants had to report their findings on an answer sheet composed of four parts:

- User's profile

- Results and follow-up of the biomimetic procedure

- Tools' evaluation (Biomimicry Taxonomy and AskNature) on a 5-point Likert scale. For each tool, five criteria, based on Nielsen's criteria about usability assessment (Nielsen 1993), were evaluated: satisfaction, learnability, error, wealth of information (derived from Nielsen criterion 'Efficiency') and precision of information (derived from Nielsen criterion 'Efficiency').

- Feedbacks from the users: What were the hardest steps you faced?

The design process used in the experiment is largely based on the unified technology pull biomimetic process (Figure 1). Due to time constraints, two modifications were made: steps 4 and 5 were gathered and students didn't deal with the 8th step, leading to a 6-step process (Figure 3).

For the second part of the study, a survey was designed and submitted to 17 experts on biomimetics. Nine of the experts came from France and the rest from a range of other countries. Their background was biology (4), architecture (4), engineering (6) and other (3). They were identified either because they took part in the scientific experts panel present at the 2018 Biomim'Expo conference in Paris, or because they are members of the CEEBIOS (Centre Européen d'Excellence en Biomimétisme de Senlis, the French association which coorganizes the Biomim'Expo conference and supports the growth of biomimicry in France) (Table 2).

The survey is twenty-five questions long but in the context of this article only two axes will be presented: Are biologists required for the practice of biomimetic? And why integrate a biologist in the biomimetic design team?

Table 2. Sample characteristics and distribution for the survey.

\begin{tabular}{lcccc}
\hline Profiles $(N=17)$ & $\begin{array}{c}\text { Researcher } \\
\text { only }(n=5)\end{array}$ & $\begin{array}{c}\text { Consultant } \\
\text { only }(n=4)\end{array}$ & $\begin{array}{c}\text { Both researcher and } \\
\text { consultant }(n=6)\end{array}$ & $\begin{array}{c}\text { Engineer only } \\
(n=2)\end{array}$ \\
\hline Master degree & 0 & 2 & 2 & 1 \\
PhD & 5 & 2 & 3 & 1 \\
Accreditation to supervise research & 0 & 0 & 1 & 0 \\
\hline
\end{tabular}




\subsection{Methods}

The protocol of the experiment remains the same for each session.

- Presentation of biomimetics and of the case study (15 min)

- Presentation of the protocol, the tools (15 min)

- Problem analysis (step 1), abstraction of technical problems (step 2) and transposition to biology (step 3) (30 min)

- Identification and selection of biological organisms or strategies on AskNature (step 4) (30 min)

- Abstraction (step 5) and transposition (step 6) of the biological solution into a technical one (20 min)

The authors then analysed users' answer sheets. Firstly, we focused on the number of determined functions (step 1), technical problems (step 2), requests (step 3) and organisms (step 4) through a quantitative (t-test) and correlation analyses (Spearman test). Because of the short duration of the experiment, the idea was not to actually find ideas for containers insulation but rather to collect data in order to evaluate the level of understanding of the users. Then, through the analysis of the abstracted strategies (step 5) and technical solutions (step 6), we tried to evaluate the understanding of biological strategies. At first, we wanted to grade the users' level of understanding of the biological phenomena, but there appeared to be too many biases to get to a relevant result. As an example, if a biologist talks about photosynthesis, even without any details, he knows what the underlying phenomena

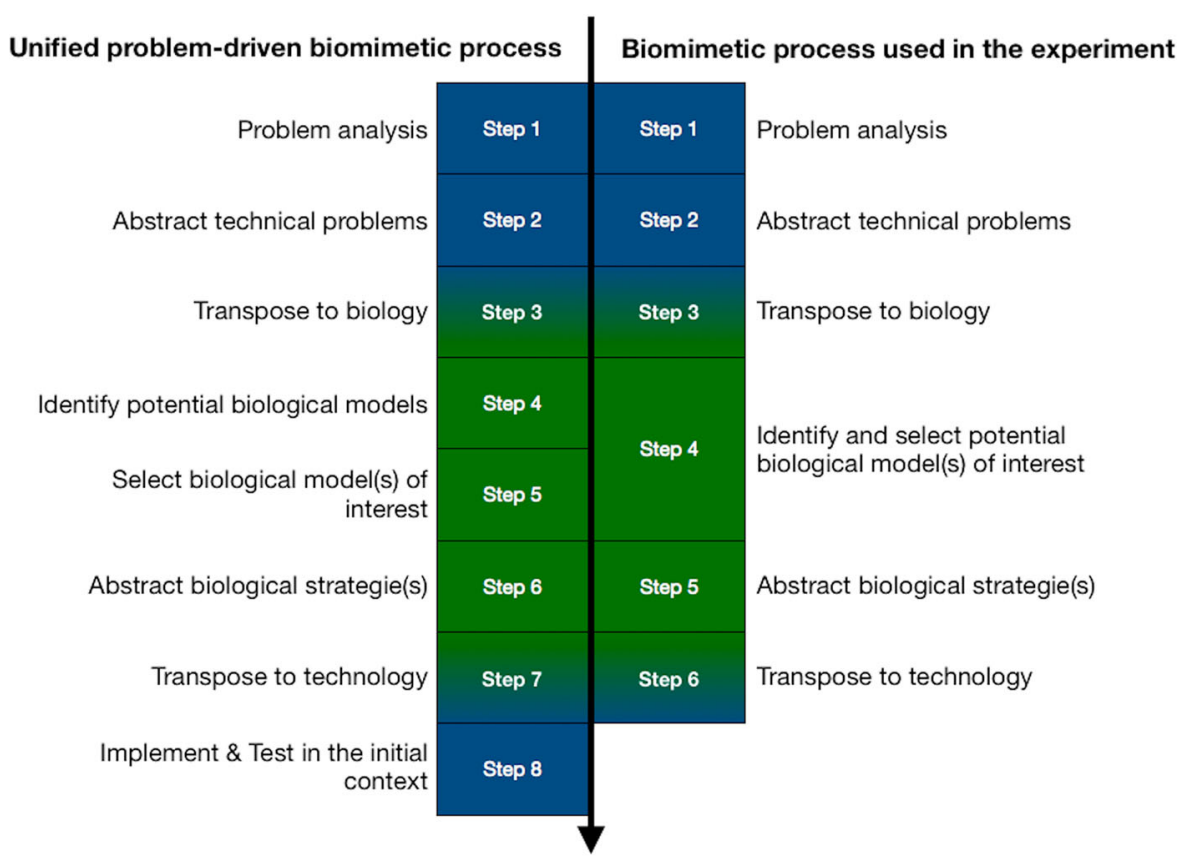

Figure 3. Comparison of the steps composing the unified problem-driven biomimetic process (Fayemi et al. 2014) and the process used in the experiment. (colour online) 
are, where an engineer doesn't. As a result, the level of understanding appeared too hard to assess without additional data.

As a consequence, we decided to focus on the biological strategies that haven't been understood, which is much easier to assess. The respective amount of misunderstood strategies will be presented for each population and compared with $\mathrm{a} \mathrm{Chi}^{2}$ test.

Furthermore, in order to help the reader, the compared results are always presented in the text formalised as follows: (biologists results vs engineers results, type of test, $p$-value:).

This analysis led us to consider a set of main tendencies that will be detailed in the next section and were used to formulate the possible answers during the design of the survey.

\section{Results}

We will look at the results obtained at the scale of the general process before analysing the results in more depth through a step by step analysis.

\subsection{Results on the global process}

For each step of the process, we will call 'identified elements' the results obtained by the users at the given step. For example, the identified elements are functions for the first step, technical problems for the second step, requests for the third step, etc.

\subsubsection{For the total population}

The number of identified elements appears to be following a two-step tendency (Table 3).

From the problem analysis (step 1) to the transposition to biology (step 3) we observe a significant increase in the number of elements given by the users whereas it significantly decreases from the identification of organisms (step 4) to the transposition to technical solution (step 6). This first pattern leads us to consider the fourth step as a bottleneck for the biomimetic process used in this experiment.

In order to get more information on this pattern, we looked at the link between the different steps through a correlation analysis (supplementary table 1). The results of the correlation analysis appear coherent with a two-part pattern, as they show strong correlations between the first three steps on one side (corr. Min. is for step 1 and 3, correlation $=0.512$, Spearman test, $p$-value $=5.10^{-04}$ ) and between the last three steps on the other side (corr. Min. is for step 4 and 6 , correlation $=0.664$, Spearman test, $p$-value $=2.10^{-06}$ ). Outside those two clusters, some correlations appear significant but they are less strong (correlations below 0.5). These tendencies support the idea that the fourth step constitutes a bottleneck for the participants at the overall scale. Interestingly, the shape of this pattern

Table 3. Paired-mean comparison of the number of elements given by the total population.

\begin{tabular}{lcccl}
\hline Elements identified at each step & Total $(N=42)$ mean $(\mathrm{stdev})$ & Mean of comparison & $P$-value (t-test) & Biomimetic tool \\
\hline 1. Functions & $5.14(1.86)$ & - & - & None \\
2. Technical problems & $6.90(2.79)$ & +1.76 & $1.10^{-08 * * *}$ & None \\
3. Requests & $9.69(5.18)$ & +2.78 & $3.10^{-05 * * *}$ & Taxonomy \\
4. Organisms & $7.35(3.05)$ & -2.33 & $2.10^{-03 * *}$ & AskNature \\
5. Biological strategies & $6.95(2.92)$ & -0.40 & $8.10^{-03 * *}$ & AskNature \\
6. Technical solutions & $5.28(2.24)$ & -1.66 & $4.10^{-05 * * *}$ & AskNature \\
\hline
\end{tabular}

P-value: ${ }^{* * * *^{\prime}}<0.001 i^{\prime * *^{\prime}}<0.01 i^{\prime * \prime}<0.05$; $^{\prime \prime}<0.1$. 
is reminiscent of the diamond-shape process of creativity, consisting of a divergent phase, where every angle of an issue is considered, before leading to a convergent phase, where the final solution is determined, within the pool of previously identified strategies.

\subsubsection{Depending on the users' background}

If we look at the same elements partitioned by backgrounds, we can see that the number of elements identified is significantly higher for biologists at each step, except at the third step (Table 4).

We then wondered about the mechanisms behind these differences, are they due to an initial higher number of elements identified by biologists that are carried over to the following steps? Or do they appear at each step? Only at specific steps?

Firstly, it appears that differences between both populations aren't significant on the number of requests formulated during the third step. However, results are significantly different during the identification and selection of potential biological models of interest, leading us to think that biologists are more efficient during this fourth step. To confirm this result, we performed a correlation analysis on biologists' results (supplementary table 2). The same two distinct phases above-mentioned (part 5.1.1. diamond shaped tendency) can be identified in the results (supplementary table 2) and the step 3 and 4 aren't significantly correlated (corr.: 0.407 , Spearman test, $p$-value $=7.10^{-02}$ ), confirming our hypothesis on the presence of at least two steps, the problem analysis and the identification and selection of potential biological models of interest, of higher efficiency linked with a background in biology.

We also performed a statistical analysis to compare the evolution of the number of elements between steps for both populations. All the differences where significant for users with a background in engineering, meaning that, as it was identified at the general level, the selection of organisms on AskNature (step 4) appears to be the first bottleneck, as the first step of significant decrease, for this population.

However, when we look at the same analysis for users with a background in biology (Table 5), we can see that the differences between steps 3 and 4, and at a higher level, between steps 4 and 5 are not significant.

It appears that a training in biology can lead to a better handling of the steps which are responsible for the decrease of the number of elements, i.e. the bottlenecks of the process. Thus, under these circumstances, the previously identified pattern appears to be modified. It is especially interesting to see that differences between the number of strategies identified from biological organisms isn't significant for biologists where it is for engineers $\left(-0.33\right.$ vs -0.45 , t-test, $p$-value $=8.10^{-02}$ vs $\left.4.10^{-02}\right)$ confirming the results underlined

Table 4. Comparison of the number of elements given at each step of the process partitioned by profile.

\begin{tabular}{lcccl}
\hline Elements identified at each step & $\begin{array}{c}\text { Biologists }(n=21) \\
\text { mean }(\text { stdev })\end{array}$ & $\begin{array}{c}\text { Engineers }(n=21) \\
\text { mean (stdev) }\end{array}$ & $p$-value (t-test) & Biomimetic tool \\
\hline 1. Functions & $\mathbf{5 . 8 5}(\mathbf{2 . 0 0})$ & $4.42(1.43)$ & $1.10^{-02 *}$ & None \\
2. Technical problems & $\mathbf{8 . 1 4 ( 3 . 1 6 )}$ & $5.66(1.65)$ & $1.10^{-03 * *}$ & None \\
3. Requests & $\mathbf{1 0 . 8 5 ( 5 . 6 6 )}$ & $8.52(4.47)$ & $1.10^{-01}$ & Taxonomy \\
4. Organisms & $\mathbf{8 . 6 6}(\mathbf{3 . 2 6})$ & $6.04(2.22)$ & $4.10^{-03 * *}$ & AskNature \\
5. Biological strategies & $\mathbf{8 . 3 3 ( 2 . 9 3 )}$ & $5.57(2.22)$ & $1.10^{-03 * *}$ & AskNature \\
6. Technical solutions & $\mathbf{6 . 4 2 ( \mathbf { 1 . 4 3 } )}$ & $4.14(2.35)$ & $5.10^{-04 * * *}$ & AskNature \\
\hline
\end{tabular}

Bold: Highest values, $P$-value: ${ }^{\prime * * \prime}<0.001 ;^{\prime * * \prime}<0.01 i^{\prime * \prime}<0.05 ;^{\prime \prime \prime}<0.1$. 
Table 5. Paired-mean comparison of the number of elements given by biologists.

\begin{tabular}{lcccl}
\hline Elements identified at each step & $\begin{array}{c}\text { Biologists }(n=21) \\
\text { mean }(\text { stdev })\end{array}$ & mean of differences & $p$-value (t-test) & Biomimetic tool \\
\hline 1. Functions & $5.85(2.00)$ & - & - & None \\
2. Technical problems & $8.14(3.16)$ & +2.28 & $4.10^{-06 * * *}$ & None \\
3. Requests & $10.85(5.66)$ & +2.71 & $5.10^{-03 * *}$ & Taxonomy \\
4. Organisms & $8.66(3.26)$ & -2.19 & $6.10^{-02}$ & AskNature \\
5. Biological strategies & $8.33(2.93)$ & -0.33 & $8.10^{-02}$ & AskNature \\
6. Technical solutions & $6.42(1.43)$ & -1.90 & $3.10^{-03 * *}$ & AskNature \\
\hline
\end{tabular}

$P$-value: ${ }^{\prime * * \prime}<0.001 ;{ }^{* * \prime \prime}<0.01 i^{\prime * \prime}<0.05 ;^{\prime \prime \prime}<0.1$.

previously. Biologists almost always transfer a biological strategy from an identified biological organism.

This overall analysis has led us to consider some quantitative differences depending on the background of the users. More especially, it showed that biologists are better equipped to face step 4 and 5 of the biomimetic process.

\subsection{Step by step analysis}

After this first analysis, we will examine the process in more depth in order to search for cognitive explanation leading to the results previously presented.

\subsubsection{Step 1. Problem analysis}

The 1st step of the experimental process aims at describing the problem through the identification of the constraints and the consumers' real needs in order to formalise technical system's functions.

During this first step, users gave a significantly different number of functions depending on the user's background (Table 4). As a result, we tried to characterise this difference by looking at the distribution of the identified functions for each background.

First of all, in total, the population with a background in biology identified 17 functions where the population with a background in engineering identified 14 functions. Moreover, even if the results don't appear significantly different, 13 functions have a higher percentage of identification by biologists (supplementary table 3). Thus, the largest number of functions identified by biologists overall is due to the accumulation of small and disseminated differences.

In conclusion, the data suggests that biologists show a greater diversity of identified functions, but don't present a strong tendency toward specific ones.

Through the analysis of each function, users had to determine a set of Technical Problems (TP) which is studied in the next section.

\subsubsection{Step 2. Abstraction of technical problems}

The 2 nd step of the experimental process aims at breaking down the identified functions into their several technical problems. For example, some users decomposed thermic insulation into the insulation from solar radiation, heat conduction, heat convection, etc.

For each function, except noise insulation, users gave a non-significantly different number of TP (supplementary table 4). We then wondered if some TP were identified specifically by one background or the other. We observed that $61.54 \%$ of them have been identified by 
both populations, $30.77 \%$ identified only by users with a background in biology and $7.69 \%$ only by users with a background in engineering ( $\mathrm{Chi}^{2}$ test, $p$-value $\left.=0.035\right)$.

Even if, as previously explained, the distribution doesn't appear significantly different overall, the TP specifically identified by biologists are divided between 10 functions, where those specifically identified by engineers represent only four functions. This leads us to think that biologists have a wider range of consideration while analysing a technical problem. The increase of diversity reduces the number of identifications for each function, and so their statistical 'weight', which can partly explain why the results aren't significant.

The identified TP are then formalised thanks to the biomimicry taxonomy into request during the third step.

\subsubsection{Step 3. Transpose to biology}

The 3rd step of the experimental process aims at transposing technical problems into biological requests through the use of the biomimicry taxonomy. For example, insulation against solar radiation have been transposed into several requests like: protect from non-living threats (light), modify light/colour, transform radiant energy, etc.

The results observed on the formulation of requests are similar than those on TP, the statistical analysis shows no significant differences on the overall functional distribution of requests. Again, if we characterise the requests, we can see that $60 \%$ have been identified by both populations, $33.3 \%$ identified only by biologists and $6.6 \%$ identified only by engineers $\left(\mathrm{Chi}^{2}\right.$ test, $p$-value $\left.=0.027\right)$. Besides, it appears for both populations that the functions targeted by the TP and the requests are similar.

Moreover, when we considered the number of identified requests by TP for each function, the comparison led us to only one function with a significant difference: the biotic insulation $\left(1.5\right.$ vs 1 , t-test, $p$-value $=7.10^{-3}$ ). At first sight, the insulation against living beings might not appear central here, but it is actually crucial in Ivory Coast and other countries where animals and especially insects like mosquitoes transmit diseases like yellow fever, dengue or malaria.

The increase in diversity induced by a background in biology and observed on the first three steps of the process is a strong argument supporting the potential for innovation brought by biologists on those engineering-centred steps.

The second part of the experiment focuses on the identification, selection and understanding of biological strategies.

\subsubsection{Step 4. Identification and selection of biological model(s) of interest}

The 4th step of the experimental process aims at identifying and selecting biological organisms by entering the requests formalised during the 3rd step into AskNature's search engine. For example, the request protect from non-living threats (light) led to the identification and selection of the Sphicterochila boisseri a specie of desert snail.

First of all, at a general scale only 12 of the 17 initial functions led to at least one organism. Among these functions, functions 1 and 2 represent $74.85 \%$ of the selected organisms. We thought of two hypotheses explaining this tight distribution. Either the results are linked with the users' choices: facing the short time frame of the experiment, they focused on the two main functions. Or, the results are linked with AskNature which doesn't display an equivalent number of, or accessibility to, organisms for each function. 
Table 6. Comparison of the characteristics of all organisms' associated strategies partitioned by profile $(n=21)$.

\begin{tabular}{lcccccccc}
\hline & $\begin{array}{l}\text { Material } \\
\text { process }\end{array}$ & Shape & Physics & Chemistry & Micro & Static & Passive & Vegetal \\
\cline { 2 - 9 } & \multicolumn{7}{c}{ Mean (stdev) } \\
\hline Biologists & $\mathbf{6 . 9 0}$ & $\mathbf{2 . 6 7}$ & $\mathbf{6 . 8 5}$ & $\mathbf{1 . 8 5}$ & $\mathbf{5 . 6 7}$ & $\mathbf{7 . 8 0}$ & $\mathbf{8 . 9 0}$ & $\mathbf{4 . 1 4}$ \\
& $\mathbf{( 2 . 7 7 )}$ & $\mathbf{( 1 . 3 1 )}$ & $\mathbf{( 2 . 2 6 )}$ & $\mathbf{( 1 . 3 5 )}$ & $\mathbf{( 2 . 4 9 )}$ & $\mathbf{( 2 . 5 8 )}$ & $\mathbf{( 3 . 0 8 )}$ & $\mathbf{( 1 . 6 8 )}$ \\
Engineers & 4.71 & 1.67 & 4.90 & 1.00 & 3.61 & 5.14 & 5.61 & 2.28 \\
& $(1.84)$ & $(1.15)$ & $(2.07)$ & $(1.14)$ & $(1.71)$ & $(2.65)$ & $(2.59)$ & $(1.84)$ \\
P-value (t-test) & $4.10^{-03 * *}$ & $1.10^{-02 *}$ & $5.10^{-03 * *}$ & $3.10^{-02 *}$ & $3.10^{-03 * *}$ & $2.10^{-03 * *}$ & $5.10^{-04 * * *}$ & $1.10^{-03 * *}$ \\
\hline
\end{tabular}

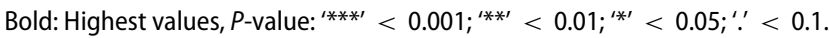

As pointed out in the table 3 , biologists gave a significantly higher mean number of organisms ( 8.66 vs 6.04 , t-test, $p$-value $\left.=4.10^{-03 * *}\right)$. In order to point out which parameters led to an identification by a particular population, we characterised the organisms' strategies. The characterisation was made on the type of associated strategy (Material/Process, Shape, System), the scientific field (Physics, Chemistry, Biology), the scale (Macro, Meso, Micro), the type of kinetic (Dynamic, Static), the energy consumption (Active, Passive) and the type of organisms (Bacteria, Fungus, Vegetal, Insects, Other animals). Table 6 displays the parameters showing significant results on the characterisation partitioned by profile.

Thus, we can see that there is a significantly higher number of organisms identified by biologists for some categories of each studied parameter, underlining their higher efficiency during the fourth step.

On the other hand, when we consider the same analysis but with proportions, there are no significant differences between the distribution of both populations suggesting that we cannot underline, based on this dataset, background-related patterns about the cognitive choices of organisms.

A first hypothesis is that the identified organisms are always the same because of their indexation, through the AskNature search engine, on the first pages of the database, leading to a smoothing of the results because of a strong redundancy.

A second hypothesis is that the selection process is driven by a parameter independent from those used in the analysis. As a result, a higher efficiency, or a lengthier time of the experiment, would lead to a higher number of identified organisms but to the same proportional distribution.

So far, these results lead us to think that biologists are more efficient during the fourth step, but no specific cognitive tendencies have been identified. In order to prevent the smoothing effect caused by the redundancy of organisms identified by both populations, we determined two categories of organisms, those specifically identified by only one profile and those identified by at least one user of both populations (Table 7).

Biologists gave a higher number of elements for both categories but again, when analysed in proportion, these differences don't appear significant. Thus, users from each background have on average the same percentage of organisms mutually and specifically identified.

In order to understand the mechanism under the specific choices made by both populations, we focused on the background-specific organisms. Overall, it appears that specific 
Table 7. Comparison of the number of organisms' associated strategies for each category partitioned by profile $(n=21)$.

\begin{tabular}{lccc}
\hline & Mean (stdev) & Mean specific (stdev) & Mean mutual (stdev) \\
\hline Biologists & $\mathbf{9 . 7 1 ( 3 . 4 0 )}$ & $\mathbf{4 . 0 0 ( 2 . 8 8 )}$ & $\mathbf{5 . 7 1 ( 2 . 0 0 )}$ \\
Engineers & $6.71(2.72)$ & $2.28(1.95)$ & $4.42(2.13)$ \\
$P$-value (t-test) & $3.10^{-03 * *}$ & $3.10^{-02 *}$ & $5.10^{-02 *}$ \\
\hline
\end{tabular}

Bold: Highest values, $P$-value: ${ }^{\prime * * \prime}<0.001 ;^{1 * * \prime}<0.01 i^{\prime * \prime}<0.05 ;^{\prime \prime \prime}<0.1$.

A.

$\%$ of all mutual $(n=213)$

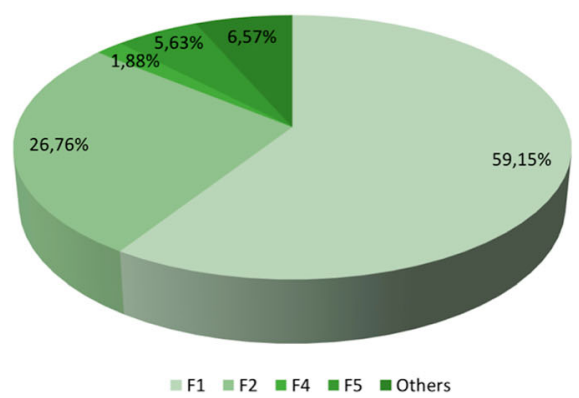

B.

$\%$ of all specific $(n=132)$

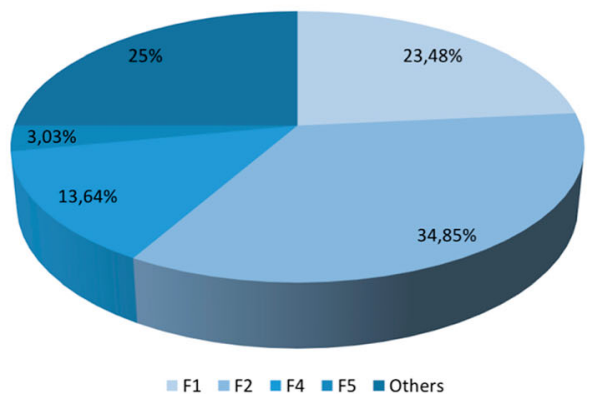

Figure 4. Comparison of organisms' functional distribution depending on 'mutual' (A) or 'specific' (B) categories. (colour online)

and mutual organisms are differentiated depending on the way they address the different functions. Figure 4 describes the organisms' partition between the four most identified functions and a cluster composed of all the other secondary functions.

Where the distribution of the organisms identified in common appears tight, centred on $\mathrm{F} 1$ and $\mathrm{F} 2$, the distribution of organisms identified specifically appears significantly different $\left(\mathrm{Chi}^{2}\right.$ test, $p$-value $\left.=1.10^{-04 * * *}\right)$ more diverse, targeting some of the secondary functions along with the main ones.

This difference of partition can also be seen on the proportion of mutually and specifically identified organisms for each function (ex for F4: $81.82 \%$ are specific, $\mathrm{Chi}^{2}$ test, $p$-value $\left.=3 \cdot 10^{-05 * * *}\right)$ (supplementary table 5$)$.

We then performed an analysis on the characteristics previously presented in order to obtain more information on the cognitive aspects of the choice of specific organisms (Figure 5).

Through this analysis, we were able to characterise the main differences between the organisms identified by both schools and those identified by only one or the other.

The next step is to compare within the specific category, the choices made by biologists and engineers. Similar to the previous analysis, if we look at the quantitative aspect, biologists and engineers gave strongly different results, but those results don't appear significantly different in proportion. The only two parameters that show significant differences in proportion are the scale (microscopic, $71 \%$ vs $56 \%, \mathrm{Chi}^{2}$ test, $p$-value $=3.10^{-2}$ ) and the energy consumption (passive, $90 \%$ vs $75 \%, \mathrm{Chi}^{2}$ test, $p$-value $=3.10^{-3}$ ), meaning that biologists drive the search for solutions toward the microscopic world and passive strategies.

In terms of the cognitive pathway, the microscopic world ultimately calls for specific knowledge where macroscopic organisms can be more easily apprehended by 


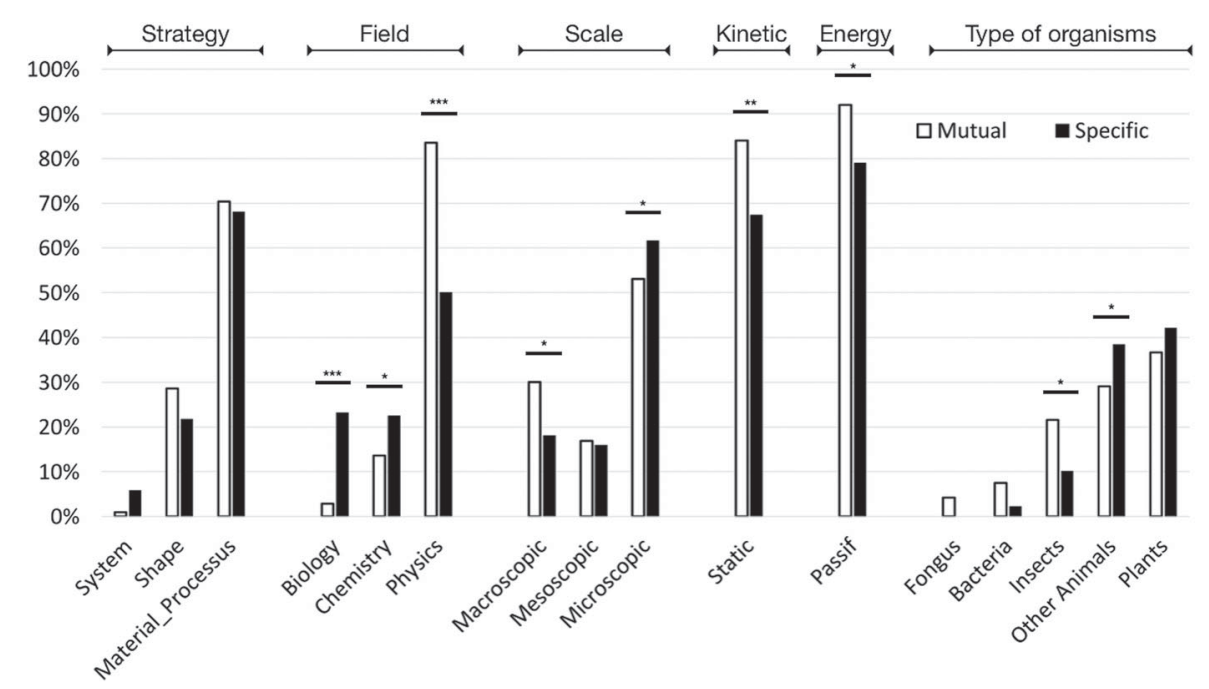

Figure 5. Comparison of 'specific' or 'mutual' organisms' associated strategies.

non-biologists, potentially explaining these results. It also shows that even within this restrictive and determined frame of research (AskNature), there is a set of organisms which identification appears background-related.

Once identified and selected, the strategies of living beings have to be analysed and understood in order to be subsequently transferred into technological innovation. As explained in part 4.2, we compared the level of understanding of these strategies by focusing on the not-understood organisms.

\subsubsection{Step 5. Abstraction of biological strategies}

The 5th step of the experimental process aims at deeply analysing AskNature's data in order to abstract the selected biological strategies. Depending on the level of understanding of the analysed strategies, the precision of the modelization varies. For example, the $S$. boisseri (desert snail) protects himself from light through a highly reflective shell. A first level of understanding would be to focus on the overall idea and so abstract the strategy by considering a protection through a highly reflective panel, but it doesn't give actual information on the reflective properties of the snail shell. A deeper level of analysis, on colours, nanostructures, shapes, etc. can lead to a more informative model and so to a more comprehensive abstraction step of the underlying biological strategy, making this 5th step a critical step of the biomimetic process.

The proportion of not understood strategies appeared significantly different depending on the background of the users $\left(0.6 \%\right.$ vs $12.3 \%, \mathrm{Chi}^{2}$ test, $p$-value $\left.=5.10^{-5}\right)$. As we can expected, the absence of a background in biology leads to a higher rate of not-understood biological strategies.

We then wondered about the distribution of these strategies. More precisely, we wanted to know if they were linked with the 'specific' or 'mutual' categories above mentioned. The results show that $64.29 \%$ of the errors (nine organisms) were made by engineers on 'specific' strategies, where no mistakes have been made by biologists on 'specific' strategies. These errors represent $18.75 \%$ of the total number of organisms specifically identified by 
engineers. As a result, biological data made available by biologists appear more relevant and reliable for the generation of abstraction model. This last result underlines that a lack of background in biology can drive the resolution process toward irrelevant or misunderstood biological strategies, resulting in the loss of resources and potentially in the failure of the innovative process implementation.

Altogether, the results of the fifth step point out the asset that represents a background in biology for the relevance and reliability of the chosen data on which is based the abstraction process of the biological strategies.

Through this step by step analysis, we pointed out the potential contribution of biologists during the biomimetic process. As previously explained, the step 6 isn't detailed in this step by step analysis. Because of the short time frame of the experiment results obtained in the step 6 were used as markers of understanding but they weren't precise enough to be separately analysed.

This article deals with the biologists' contribution during the practice of biomimetics in order to foster his integration during both the practice of biomimetics and the design of the method and tools. As a result, we also investigate the users' feedbacks toward the tools used during the experiment in order to underline any shortcomings.

\subsection{Tool analysis and users' feedbacks}

The tools' evaluation was performed by the users with a 5-point Likert scale on satisfaction, learnability, error, wealth of information and precision of information. Firstly, we evaluated the Biomimicry Taxonomy (Table 8).

As we can see in Table 8, the Biomimicry Taxonomy obtained overall positive grades. The precision and wealth of information are the criteria which obtained the lowest grade for both populations underlining some of the feedbacks given by the users: The taxonomy limits the reflection, Hard to find matching requests for some of the TP. We can see that the only criterion which obtained a significantly different grade is the wealth of information (MMW test, $p$-value $=2 \cdot 10^{-3 * *}$ ). These results lead us to think that even if engineers acknowledged the diversity of the requests available through the taxonomy, they didn't find the tool very precise and had troubles formulating requests addressing the identified TP directly. On the other hand, biologists felt restricted by the tool in both its diversity and precision.

We then evaluated AskNature following the same protocol (Table 9).

AskNature's ease of access has been underlined by all users. Interestingly, engineers gave high scores on all criteria during AskNature's evaluation, with a significant difference comparing to biologists on its precision (MWW test, $p$-value $=2.10^{-3 * *}$ ) (Figure 6).

On one hand, engineers say the tool is rich, precise and satisfying. On the other hand, biologists show a mixed opinion on the wealth of information and the precision of the tool. Two main hypotheses can explain such results.

Table 8. Biomimicry Taxonomy's evaluation by both profiles $(n=21)$.

\begin{tabular}{lccccc}
\hline & Learnability & Errors & Wealth of information & Precision & Satisfaction \\
\hline median (biologists) & 4 & 4 & 3 & 3 & 4 \\
median (engineers) & 4 & 4 & $\mathbf{4}$ & 3 & 4 \\
$p$-value (MWW test) & $6.10^{-1}$ & $4.10^{-1}$ & $2.10^{-3 * *}$ & $8.10^{-1}$ & $3.10^{-1}$ \\
\hline
\end{tabular}

$P$-value: ${ }^{* * * \prime}<0.001 ;^{* * \prime}<0.01 ;^{* *^{*}}<0.05 ;^{\prime \prime}$ ' $<0.1$. 
Table 9. AskNature's evaluation by both profiles $(n=21)$.

\begin{tabular}{lccccc}
\hline & Learnability & Errors & Wealth of information & Precision & Satisfaction \\
\hline median (biologists) & 5 & 4 & 4 & 3 & 4 \\
median (engineers) & 5 & 4 & 4 & $\mathbf{4}$ & 4 \\
$p$-value (MWW test) & $9.10^{-2}$ & $7.10^{-1}$ & $1.10^{-1}$ & $2.10^{-3 * *}$ & $7.10^{-1}$ \\
\hline
\end{tabular}

P-value: ${ }^{* * * \prime}<0.001 i^{* * \prime}<0.01 i^{* * \prime}<0.05 ;^{\prime \prime} .<0.1$.

A.

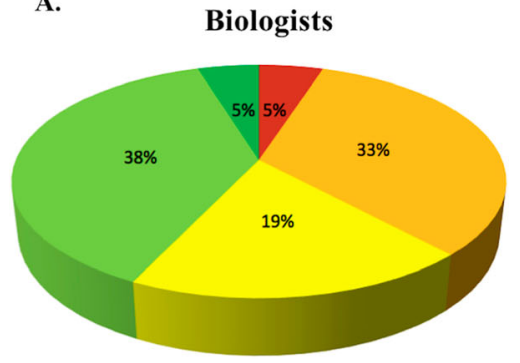

B.

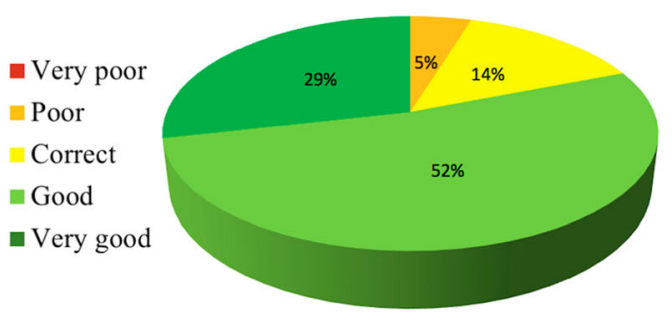

Figure 6. Comparison between scores given by biologists (A) and engineers (B) on AskNature's precision. (colour online)

Firstly, because of the differences on their respective knowledge in biology, both populations don't have the same expectations for such a tool. As the database does not list all known organisms and does not provide enough information to understand all the phenomena, biologists felt frustrated the search engine restrains imagination, the website limits, frames and offers very little ideas and gave lower scores during its evaluation. Where biologists are already aware of the diversity and complexity of biological strategies, engineers might feel overwhelmed by data they aren't accustomed to deal with. Hence, this feeling can lead to a Wahoo effect driving engineers to over-rate the tool. As a result, the lack of a background in biology leads to a variation in the frame of reference which is a break in the innovative process because it will narrow the spectrum of research and hence the potential for novelty.

A second aspect is that engineers and biologists may not have the same goal while using the data. The reasoning processes of biologists and engineers intrinsically differ in their objectives: where the main objective of biologists is to discover and understand how entities work, the main objective of engineers is to innovate and design new entities. These fundamentally different aims influence their reasoning, habits and insights when facing data. During the biomimetic design process, engineers may consider biological phenomena as a source of inspiration to be used during creativity steps rather than a source from which they can directly extract technical innovations. Thus, the expectations on the depth of understanding, and, therefore, the diversity and precision of the data, can vary, which might explain the results.

\section{Comparison with experts' opinion}

As presented in section 4, the results that are discussed in this section focus on only two axes of the survey. The first question was about the 'necessity' of biologists during the 
practice of biomimetics. As the term necessity appears quite restrictive, we expected a mitigate answers by the experts. Three answers were available: 'Yes', 'No', 'Depends on the project'. $53 \%$ of the respondents indicate that the necessity of a biologist during the practice of biomimetics depends on the project, $41 \%$ answered 'Yes' and 6\% answered 'No'. It is essential to underline that they nonetheless all recognise the asset that represents a biologist during the practice of biomimetics. When asked why biologists aren't necessary during the biomimetic design process, experts point out three main aspects. First, the available biological data might be detailed and clear enough to be understood by non-biologists. Secondly, some design projects don't require a deep understanding of the biological strategy to successfully meet their goals. And finally, the biological expertise doesn't have to be necessarily provided by a biologist but can be a skill own by another profile.

When we consider a parallel between the results of our case study and the answer to the survey, we can see that in both situations, an expertise in biology emerge as an asset for the practice of biomimetics and the understanding of biological data. Moreover, the existence of several levels of inspiration depending on the background, is also supported by both the results from the case study and the survey. Finally, the question of the holder of the biological knowledge emerges as fundamental and will be detailed in the discussion part.

The second question is about the role of biologists during the biomimetic process. The results from the case study allowed us to identify three main contributions: the ability to provide a deep understanding of biological data, to make reliable choices, and to offer diversity during the engineering centred steps thanks to an alternative way of reasoning. In order to evaluate the relevance of our findings, we proposed five different answers (and an 'other' response) and restricted to a maximum of three answers by the respondent (Figure 7).

These results support two of our findings as they both the understanding and the identification show more than $80 \%$ of the selection. Interestingly, no experts identified missing aspects. Specifically, the biologist's ability to add variability isn't identified if not proposed. Taken together with our first results, this aspect suggest that the added variability observed during the case study is presumably not specific to biologists. It is indeed a well-known fact in design that pluridisciplinarity in general helps overcome fixations and brings diversity. However, biologists do bring variability and as a result it can be considered as an added-value, even if non-specific. Experts also pointed out the biologists' role as bridges between biology and engineering through the translation of biological vocabulary and concepts. This aspect hasn't been studied in the case study as the experiment was performed individually.

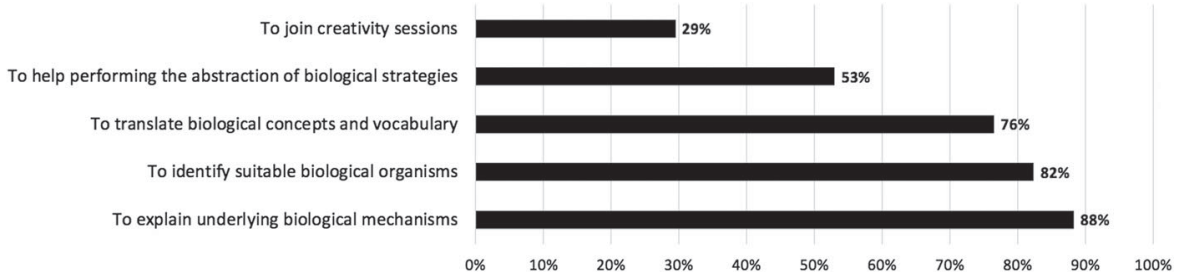

Figure 7. Experts' opinion on the contribution of biologists during biomimetic process. 
Altogether, the experts' opinion, strengthen our analysis on the asset that represents an expertise in biology for the biomimetics process. The next part will discuss our findings, their relevance, their consequences as well as our future axes of research.

\section{Discussion}

This article presented the contribution of biologists during the biomimetic design process through a case study and a survey of experts' opinion. Our results underlined why biologists represents assets and so levers for optimisation for the biomimetic design process.

Nevertheless, several limitations have to be pointed out. First, the case study has been performed by the individual student and not interdisciplinary teams. As a result, both positive or negative aspects of interdisciplinary work, like constructive interactions or communication challenges, aren't taking into account in this study.

Furthermore, this article doesn't tackle one other challenging step of the biomimetic process which concerns the means of identification of biological organisms. Indeed, only AskNature was used as the source of organisms but as previously underlined, even if it represents the greatest biomimetic database available, AskNature is very restrictive. Without AskNature, is an engineer able to find organisms of interest? The strong concurrence in the industrial context will lead biomimetic teams to consider much more organisms than those listed on AskNature, pointing out another strong need for biological expertise.

The short time frame of the study and the fact that, even if supported by experts' answers, the sample is composed of students and not professionals have to be taken into consideration. In that respect, we are currently working on a long-term project with industrial partners in order to confirm our findings, test new hypotheses and methodological innovations.

Finally, the design problem chosen in this article is easily accessible because not very technical. Therefore, it has to be considered that these results are linked with the studied subject. Notably, the steps 1-3 are well managed by biologists and steps 4-6 are well managed by engineers, all partially due to the topic of the case study which was easily accessible. We are aware of those biases but, since it makes technical issues more accessible for both populations, an easy design problem might reduce the gaps between both populations rather than exaggerate them, and so doesn't represent a problematic factor in this context.

Our findings open several research axes. Where this article aims at foregoing the integration of biological expertise, it doesn't show that biologists can replace engineers. Each profile brings its own specificities and we believe that it is the cooperation between both profiles that will lead to a successful implementation of biomimetics.

The terms and form of such a cooperation are to be entirely defined. As pointed out by the experts: should we actually consider the integration of 'biologists' or of 'biological expertise' and if we are, which 'biologists' are we talking about? A transdisciplinary profile, having both a biological expertise, focused on the needs of biomimetics design, and knowledge in engineering in order to link both scientific fields appears as a challenging but rewarding research goal. It also raises the question of the methodological framework surrounding the integration of such a profile. As our findings suggest, an expertise in biology should facilitate the access to a deeper level of analysis but it also requires tools and processes adapted for such approaches and pluridisciplinary work. 


\section{Conclusion}

Biomimetics isn't a new strategy but its implementation remains highly limited in the industrial sector. Our first assessment is that industrial companies that want to use biomimetics as an innovation strategy need guidance. The complexity and transdisciplinary aspect of this approach cannot be ignored or considered secondary. Biomimetics' complexity and novelty potentially require new profiles, structural evolutions and specific training. More specifically, our observation is that the current methodological framework is based on biomimetic tools without taking into account biologists' expertise, leading to processes that aren't made to be transdisciplinary in practice.

However, we also pointed out that numerous researchers underlined the necessity of biologists during biomimetic processes. This contradiction raises the research question tackled in this article: Facing the current biomimetics' methodological framework, does knowledge in biology represent an asset for the practice of biomimetics? Our hypothesis is that it does. The results presented in this article underlined two main aspects. Firstly, biologists appear to be more effective during the use of biomimetic tools as they've found more elements and have made less mistakes. Secondly, both biologists and engineers bring their way of reasoning leading to an increase in the diversity of identified biological models. These results are supported by experts' opinion gathered through a survey and so validate our hypothesis. By showing, in an accessible and restricted context, that biologists expertise contributes to the innovative nature of biomimetics, these findings contribute to the consideration, by engineering designers, of biologists' role during the design of a transdisciplinary methodological framework for the practice of biomimetics. Choosing between the development of biomimetic tools and the integration of biological expertise has proven to be a mistake as biomimetics is still struggling to spread in the industrial world. We advocate that both aspects need to be investigated and combined in order to solve the current paradoxical situation and take biomimetics to the next level.

This article is built as the foundation stone for our future work on biomimetic design teams, process and tools, combining expertise in engineering and biology. In this perspective, our coming work focuses on collecting information about engineers' and biologists' needs during the biomimetic process in order to identify key elements obstructing the integration of a profile with a background in natural sciences. We will then work on providing a more precise methodological support, discussing the biological knowledge of interest in order to target which profile to integrate in biomimetic teams, when and for what purpose should they be integrated, and using which tools. The overall aim of our work is to optimise the methodological framework within a transdisciplinary context in order to guide industrial actors who want to implement biomimetics as an innovation strategy.

\section{Acknowledgments}

We thank the students who took part in our experiment and the respondents to our questionnaire. Special thanks to Juliette Gambaretti for her guidance and support on statistical analyses.

\section{Disclosure statement}

No potential conflict of interest was reported by the authors. 


\section{ORCID}

Eliot Graeff (iD http://orcid.org/0000-0002-8437-5699

Nicolas Maranzana (i) http://orcid.org/0000-0002-1982-9041

\section{References}

Ahmed-Kristensen, S., B. T. Christensen, and T. A. Lenau. 2014. "Naturally Original: Stimulating Creative Design Through Biological Analogies and Random Images." In Design Conference, 427-436. Dubrovnik: Design Society.

Altshuller, G. S. 1984. Creativity as an Exact Science: The Theory of the Solution of Inventive Problems. New York: Gordon and Breach Science Publishers.

Bar-Cohen, Y. 2006. "Biomimetics - Using Nature to Inspire Human Innovation." Bioinspiration and Biomimetics 1 (1): P1-P12. doi:10.1088/1748-3182/1/1/P01.

Bar-Cohen, Y. 2012. "Biologically Inspired Technologies for Aeronautics." In Innovation in Aeronautics, 15-36. Woodhead Publishing. doi:10.1533/9780857096098.1.15.

Baumeister, D. 2014. Biomimicry Resource Handbook: A Seed Bank of Knowledge and Best Practices. 2014th ed. Missoula: CreateSpace Independent Publishing Platform.

Benyus, J. M. 1997. Biomimicry: Innovation Inspired by Nature. New York: Quill.

Bila-Deroussy, P. 2015. "Systemic Approach of Creativity: Tools and Methods to Address Complexity in Design." ENSAM - Paris.

Biomimicry Institute. 2002. "AskNature - Innovation Inspired by Nature." AskNature. https://asknature. org/.

Boeuf, G. 2007. "Océan et Recherche Biomédicale." Journal de la Société de Biologie 201 (1): 5-12. doi:10.1051/jbio:2007001.

Bourgeois, P. 2007. Les grands défis technologiques et scientifiques au XXle siècle. Ellipses.

Chakrabarti, A., P. Sarkar, B. Leelavathamma, and B. S. Nataraju. 2005. "A Functional Representation for Aiding Biomimetic and Artificial Inspiration of New Ideas." Artificial Intelligence for Engineering Design, Analysis and Manufacturing: AIEDAM 19 (2): 113-132. doi:10.1017/S08900604050 50109.

Chirazi, J., K. Wanieck, P. E. Fayemi, C. Zollfrank, and S. Jacobs. 2019. "What Do We Learn From Good Practices of Biologically Inspired Design in Innovation?" Applied Sciences 9 (4): 650. doi:10.3390/app9040650.

Deldin, J. M., and M. Schuknecht. 2013. "The AskNature Database: Enabling Solutions in Biomimetic Design." In Biologically Inspired Design, 17-28. London: Springer.

Eggermont, H. 2015. "Nature-Based Solutions: New Influence for Environmental Management and Research in Europe." GAIA - Ecological Perspectives for Science and Society 24 (4): 243-248. doi:10.14512/gaia.24.4.9.

Faludi, J. 2017. “Golden Tools in Green Design: What Drives Sustainability, Innovation, and Value in Green Design Methods?" University of California Berkeley. https://digitalcommons.dartmouth.edu/ facoa/2784.

Fayemi, P. E. 2016. "Innovation through Bio-Inspired Design: Suggestion of a Structuring Model for Biomimetic Process and Methods." ENSAM - Paris.

Fayemi, P. E., N. Maranzana, A. Aoussat, and G. Bersano. 2014. "Bio-Inspired Design Characterisation and Its Links with Problem Solving Tools." In Design Conference, 173-182. Dubrovnik: Design Society.

Goel, A. K., S. Vattam, B. Wiltgen, and M. E. Helms. 2014. “Information-Processing Theories of Biologically Inspired Design." In Biologically Inspired Design, 127-152. London: Springer.

Gordon, W. J. J. 1961. Synectics - The Developmnent of Creative Capacity. New York: Harper \& Row.

Grabowski, H., R. S. Lossack, and E. F. El-Mejbri. 1999. "Towards a Universal Design Theory." In Integration of Process Knowledge Into Design Support Systems, 47-56. Dordrecht: Springer.

Guerrero, J. E., D. Maestro, and A. Bottaro. 2012. "Biomimetic Spiroid Winglets for Lift and Drag Control." Comptes Rendus - Mecanique 340 (1-2): 67-80. doi:10.1016/j.crme.2011.11.007.

Helfman Cohen, Y., and Y. Reich. 2016. "Biomimetic Design Method for Innovation and Sustainability." Biomimetic Design Method for Innovation and Sustainability, doi:10.1007/978-3-319-33997-9. 
Hoagland, M. B., and B. Dodson. 1995. The Way Life Works. 1st ed. New York: Crown.

Hwang, J., Y. Jeong, J. W. Hong, and J. Choi. 2015. "Biomimetics: Forecasting the Future of Science, Engineering, and Medicine." International Journal of Nanomedicine 10: 5701-5713.

IPCC. 2014. "Climate Change 2014: Synthesis Report. Contribution of Working Groups I, II and III to the Fifth Assessment Report of the Intergovernmental Panel on Climate Change on Climate Change." IPCC, Geneva, Switzerland.

ISO/TC266. 2015. "Biomimétique -Terminologie, Concepts et Méthodologie." https://www.iso.org/fr/ committee/652577/x/catalogue/.

Keshwani, S., T. A. Lenau, S. Ahmed-Kristensen, and A. Chakrabarti. 2017. “Comparing Novelty of Designs From Biological-Inspiration with Those From Brainstorming." Journal of Engineering Design 28 (10-12): 654-680. doi:10.1080/09544828.2017.1393504.

Lahonde, N. 2010. “Design Process Improvement: Proposal of a Model for Design Methods Selection to Support the Decision." ENSAM - Paris.

Lee, J., J. Pries-Heje, and R. Baskerville. 2011. "Theorizing in Design Science Research." In Proceedings of the 6th International Conference on Service-Oriented Perspectives in Design Science Research, 1-16. Berlin: Springer-Verlag.

Lenau, Torben Anker. 2009. "Biomimetics as a Design Methodology - Possibilities and Challenges." International Conference on Engineering Design, ICED, 121-132.

Lindemann, U., and J. Gramann. 2004. "Engineering Design Using Biological Principles." In Design Conference, 355-360. Dubrovnik: Design Society.

Magyar, A., V. K. A. Arthanareeswaran, L. Soós, K. Nagy, A. Dobák, I. M. Szilágyi, N. Justh, A. R. Chandra, B. Köves, and P. Tenke. 2017. “Does Micropattern (Sharklet) on Urinary Catheter Surface Reduce Urinary Tract Infections? Results From Phase I Randomized Open Label Interventional Trial." European Urology Supplements 16 (3): e146-e148. doi:10.1016/S1569-9056(17)30153-7.

Nagel, J. K. S., R. L. Nagel, R. B. Stone, and D. A. McAdams. 2010. "Function-Based, Biologically Inspired Concept Generation." Artificial Intelligence for Engineering Design, Analysis and Manufacturing: AIEDAM 24 (4): 521-535.

Nielsen, J. 1993. Usability Engineering. London: Academic Press.

Ohno, T. 1978. Toyota Production System: Beyond Large-Scale Production. 1st ed. Vol. 1. Cambridge, MA: Productivity Press.

Richter, I. A., T. Wells, and M. Kemp. 2008. Notebooks. Oxford World's Classics. New Edition. Oxford: Oxford University Press.

Sachs, J. D. 2015. The Age of Sustainable Development. Columbia University Press. doi:10.7312/sach 17314.

Schöfer, M. 2015. "Processes and Methods for Interdisciplinary Problem Solving and Technology Integration in Knowledge-Intensive Domains." ENSAM - Paris.

Schöfer, M., N. Maranzana, A. Aoussat, G. Bersano, and S. Buisine. 2018. "Distinct and Combined Effects of Disciplinary Composition and Methodological Support on Problem Solving in Groups." Creativity and Innovation Management 27 (1): 102-115. doi:10.1111/caim.12258.

Snell-Rood, E. 2016. "Interdisciplinarity: Bring Biologists Into Biomimetics." Nature 529 (7586): 277-278. doi:10.1038/529277a.

Tinsley, A., P. Midha, R. L. Nagel, and D. A. McAdams. 2007. "Exploring the Use of Functional Models as a Foundation for Biomimetic Conceptual Design." ASME 2007 International Design Engineering Technical Conferences and Computers and Information in Engineering Conference, 1-15. doi:10.1115/DETC2007-35604.

Vandevenne, Dennis, Paul Armand Verhaegen, Simon Dewulf, and Joost R. Duflou. 2015. "A Scalable Approach for Ideation in Biologically Inspired Design." Artificial Intelligence for Engineering Design, Analysis and Manufacturing: AIEDAM 29 (1): 19-31. doi:10.1017/S0890060414000122.

Vincent, J. F. V., O. A. Bogatyreva, N. R. Bogatyrev, A. Bowyer, and A. K. Pahl. 2006. "Biomimetics: Its Practice and Theory." Journal of the Royal Society Interface 3 (9): 471-482. doi:10.1098/rsif.2006.0127.

Wanieck, K., P. E. Fayemi, N. Maranzana, C. Zollfrank, and S. R. Jacobs. 2017. Biomimetics and its Tools, Bioinspired, Biomimetic and Nanobiomaterials 6 (2): 53-66. doi:10.1680/jbibn.16.00010.

Zhang, G. 2012. "Biomimicry in Biomedical Research." Organogenesis 8 (4): 101-102. doi:10.4161/org. 23395. 